\title{
COLLABORATION BETWEEN THE V.D. AND OTHER SPECIAL DEPARTMENTS*
}

\author{
By CLAUDE A. MILLS, M.R.C.S., L.R.C.P., Surgeon to St. Paul's \\ Hospital and Director of the Clinic for Venereal Diseases
}

THE very name " Venereal," with which our Specialty is cursed, has always been, and will probably remain, a very potent factor in inhibiting whole-hearted sympathy and encouragement both from the general public and the medical profession.

That the study of venereal diseases is now a firmly established and recognised specialty is due to the very important bacteriological, pathological, chemical, biochemical and clinical researches which have been devoted to it, and further also to the fact that proficiency in the carrying out of modern methods of diagnosis and treatment demands special training and experience.

Although much has been done recently, especially since the War, to strip off the cloak of hypocrisy under which the whole subject of venereal diseases was shrouded, it seems that many years must pass before the topic will be as openly discussed in lay circles as are the recent advances in the control of cancer or tuberculosis.

The fact that the vast majority of venereal infections are the direct sequence-and therefore positive proof ofimmorality, will always be the big factor in sustaining the view held in pious circles-that V.D. is the just earthly reward for the sinner-and as such, deserving of scanty, if any, sympathy from the righteous.

The country contains too many who feel that " to throw the first stone" is their day's good deed, which carries with it the ear-mark of the virtuous rather than that of the hypocrite.

The challenge, " why should the innocent be allowed to suffer preventable congenital stigmata ?" is usually countered by an allusion to the visitation upon the third and fourth generation of a sinful parent-a clinical phe-

* A paper read before the Medical Society for the Study of Venereal Diseases, April 27th, I934. 


\section{BRITISH JOURNAL OF VENEREAL DISEASES}

nomenon which I have never met, at least on the paternal side-where the laity usually place the blame.

In the same pious circles, the innocently acquired infections are dismissed merely as consequences to be expected in those who must be as lax in the selection of their associates as they probably are in their habits.

Much progress will have been made in sociology when the V.D. patient is universally regarded as an unfortunate, rather than a guilty, member of the community.

Nor can the medical profession, though fully conscious of the constant wastage from V.D. in both the civil community and fighting forces, be entirely dissociated from the above smug ostracism.

It is almost impossible nowadays for us to realise the crass indifference of the medical profession, as a whole, to V.D. in the comparatively recent past. It would appear that, outside of the very few special hospitals in the country, syphilis was treated with a box of pills and disgust, and gonorrhœa with disgust only. The quack and the herbalist must have fattened upon those wretched patients who were driven to them for help and sympathy. The old army surgeon, with all due respect, was the doctor usually most accredited with a broad-minded and practical experience in the subject-not necessarily from choice. And by comparison, those must be considered fortunate who consulted him.

The terms " clap doctor" and "The Pox Hospital" have certainly not originated out of any response suggestive of skill or respect, and in public esteem became indicative of a status but slightly superior to that held by the criminal abortionist and the common gaol respectively.

More recently, some have endeavoured to sustain respectability whilst specialising in V.D. by adopting the title of Dermatologist, which rather suggests " running with the fox whilst hunting with the hounds." It has always rather intrigued me as to how such gentlemen can justify their adoption of such an exclusive title whilst coping with a case of, say, prostatic abscess, acute iritis, or a fractious G.P.I.

The above observations tend to indicate that the unfortunate V.D. patient, and those who look after him, have had what might be termed in another country, a "tough break" in the past. 
Not that I am suggesting that the V.D. patient should be in any sense pampered or privileged, nor in fact have any concessions more generous than those extended to him to-day in this country, namely, a grid-system of free-treatment centres, staffed by specially trained M.O.'s - provided and maintained out of the pockets of his more fortunate, and often less selfish, fellow countrymen. Out of the very unsatisfactory conditions which obtained in the past there has gradually evolved the present recognition of " the social scourge," and what is more important, a systematic and well-regulated scheme to deal with it.

If we look back we are reminded that with the advent of that great pioneer-Sir Jonathan Hutchinson-whose descriptions of his clinical observations still make such fascinating reading, even in the light of subsequent discoveries - the study of syphilis was granted a higher status. The " pox doctor became the Syphilologist," and the " two years' course of Hutchinson's pills" would seem to be the first attempt at formulating some scheme of treatment in this country.

Later, the work and writings of Sir Frederick Mott upon neuro-syphilis greatly enhanced the importance of this branch of our specialty.

It is possible that "Lambkin's Cream" does not convey to some of us that Colonel Lambkin was the first to systematise the treatment of syphilis in the British Army. Lambkin originated the scheduling of definite courses of intra-muscular injections of the grey-oil, using creo-camph as a base, and from which it became possible to assess results in the follow-up of cases treated systematically. In civilian clinics the value of Lambkin's therapeutic register was soon appreciated. In comparison with the haphazard treatment with pills or selfinunction, the administration of which rested entirely with the patient, weekly mercurial injections placed the control as to dosage and interval in the hands of the M.O. This is more important in the history of the formation of special V.D. departments in general hospitals than might at first appear. It necessitated the weekly attendance of a number of patients, for convenience on the same day, and for which space had to be set aside-probably in the lower basement, or an out-house where the gonorrhoeal cases could be also safely hidden away; but it 


\section{BRITISH JOURNAL OF VENEREAL DISEASES}

was the start of a new department which we of to-day are entitled to call Special, Special because the work entails experience in technique now employed in diagnosis and treatment, thus rendering it beyond the scope of the general physician and surgeon, and to which other departments are compelled to refer.

I may appear to have wandered somewhat from the subject, but what I wish to emphasise-and it will at once be apparent to you all-is, that before there can exist a satisfactory collaboration between special departments, there must be a mutual appreciation of values of the services rendered.

I am confident that you will agree with me when I express the opinion that to no one is the position held to-day by our specialty more responsible than to Colonel Harrison. The Society should feel as proud of having had him for its President upon two occasions as I am of having worked with him for five years in the past.

In the same category, I am sure that you would wish me to refer to my dear old friend and colleague-David Lees. Here again we are fortunate in having had him twice as our President-we shall deeply miss his cheerful and lovable personality as much as his useful and valuable services. Although his organising and administrative activities were pursued primarily in Scotland, their effect could be felt much further afield. His unsparing energy and unlimited enthusiasm could not fail to be infectious to all with whom he came in contact-and they were many. His sudden demise at the height of activity has created a void very difficult ever to fill, but such a man carried momentum. Lees also did much to raise the prestige of our specialty.

Now consider the reciprocal working of the V.D. and other departments. First arises the contentious question as to whether it is more advantageous for a V.D. clinic to exist as a special department of a general hospital, or as a self-contained separate unit.

For the former, its advocates will insist that attendance is facilitated for the sensitive V.D. patient, since his entrance to a general hospital does not indicate to others that his complaint is necessarily venereal ; that duplication of existing laboratories and dispensaries, etc., is obviated; and again that collaboration with other departments is encouraged by proximity. The sup236 


\section{COLLABORATION BETWEEN THE V.D., ETC.}

porters of the separate unit, though usually admitting that there is something to be said for the above views in theory, stubbornly assert that they are not borne out in practice, and support their contention by naming instances of a vast and increasing turnover in the number of patients at dissociated treatment centres. Upon the question of a separate laboratory and dispensary for the special requirements, and proximity, there are advocates in both camps, as there surely must also be with regard to mutual benefit when other special departments are housed in the same building.

Personally, I have found that a sound practical combination is formed by grouping the Genito-Urinary, Skin and the V.D. departments together in the one building. The overlap in the three specialties creates interdependence. It not infrequently happens that the same patient may be attending all three departments, and there is no knowing for which disability he originally sought advice. A tabetic with a neuro-trophic bladder might first attend for some skin complaint (patients with impaired urinary excretion are notoriously prone to eczematous conditions); a non-specific urethritis resulting from stricture may bring a patient first to the V.D. department; the old tertiary syphilitic is frequently found to have a co-existing urinary complaint - either of which might be the first to be discovered. Many are the occasions when a patient will attend for a skin complaint which he fears may be syphilitic-in some instances correctly, but far more frequently not so. Further investigation may prove, that although the present lesion is not specific, the patient may have been infected in the past, of which fact he may, or may not, be ignorant. The development of any skin lesion is probably the commonest incentive in causing the old syphilitic to seek advice which he otherwise would not; the outward and visible sign has shaken his indifference. Here a close collaboration between the two departments is essential.

In some instances the V.D. department had originated as an offshoot of the G.-U. department. Here there should exist complete harmony, which in my opinion would be more universally obtained if every G.-U. surgeon were possessed of practical experience in V.D. work. What better grounding could he have for his specialty than the experience gained from the rigorous duties necessitated 


\section{BRITISH JOURNAL OF VENEREAL DISEASES}

in the V.D. department? Competency demands speed and accuracy in systematic clinical examination and note taking, and an appreciation of the normal external genitalia, urethra, prostate and vesicles from the abnormal and of the new growth from changes resulting from inflammatory processes. Yet I have frequently heard it stated by an applicant for the post of house-surgeon that he has not, nor does he desire any experience in V.D. work, his ambition being to become a "pure" G.-U. surgeon. There would appear still to exist the suspicion that some loss of prestige might result from an early association with the V.D. departments, or a belief that the two specialties can be entirely dissociated.

It is an advantage, both to patient and M.O., if there is a minimum of delay in obtaining the opinion for which a case is sent to another department, and this is more likely to occur when the departments are in the same building, and further, should it be found necessary for him to attend more than one department for treatment, this can usually be arranged at one visit.

With regard to the laboratory, where practicable, I am in favour of having it in the same unit. Time, and possibly error, are reduced when the transit of specimens and reports by post or messenger are obviated. A close co-operation between the clinician and the laboratory worker bids for increased interest and efficiency in each. Investigations under laboratory control are facilitated; what hitherto has been a mere number to the laboratory worker becomes at once an interesting clinical entity after a friendly chat upon a difficult case with the M.O. concerned. There is a tendency amongst some clinicians to regard the laboratory worker as somewhat of a recluse, lacking in soul and imagination-almost an automatonwhose communications with the outer world begin and end with a laboratory report, and what he cannot see in a test-tube, on a culture medium, or down a microscope fails to interest him entirely. On the contrary, I have always found them to be extremely pleasant and helpful gentlemen-if approached in the right way-many of them are perhaps a trifle stubborn, and might appear to come from the North-but very appreciative if their advice is sought, when nothing is too much trouble.

And now a few words upon the question of Segregation of patients attending the V.D. department from those 


\section{COLLABORATION BETWEEN THE V.D., ETC.}

attending others. One never hears the clamour raised for segregation by the idealists where the clinic is an isolated unit, under the assumption that the patient attending a V.D. clinic is deserving of no such niceties.

Personally, I think that the risk of other patients becoming contaminated with V.D. whilst attending a hospital where a V.D. department exists is a bogey. Were the aseptic precautions in force in every modern V.D. clinic insufficient, then we should all be seeing our syphilis cases accidentally infected with gonorrhœa from time to time, and vice versâ. And again, out of that enormous total composed of patients who attend for examination and upon the completion of which are proved to be free from V.D.- surely we should meet with accidental infections amongst these were it rendered possible-yet we do not, nor do these occur amongst our staff.

I consider that the only practical advantage that may be derived from segregating the V.D. patients from those attending other departments in the same building, more especially with regard to the waiting rooms, dispensary, canteen and lavatories, would result from the fact that under these circumstances gossip amongst patients would be reduced to a minimum. With all due respect, I would emphasise that this is of greater importance amongst women patients. It might perhaps lessen the facilities for obtaining evidence of utility to the potential blackmailer. Actually I have only heard of one genuine complaint with regard to the common waiting room in a hospital where there is a V.D. clinic. A doctor complained that a very nervous patient whom he had sent up for investigation for suspected renal tuberculosis was horrified to find that he was sitting next to a filthy person who vividly described his gonococcal complications, and the treatment likely to be handed out to the new patient when his turn arrived, and for which I understand he did not wait. I still maintain, however, that this patient might just as easily have sat next to a case of scarlet fever, scabies or diphtheria under any other system of reception upon the initial attendance of the, as yet, undiagnosed case. For segregation to be thorough, it should be commenced before the patient leaves his own home. The risk of a patient contracting V.D. accidentally is far greater in his every-day habits of life 


\section{BRITISH JOURNAL OF VENEREAL DISEASES}

than during his attendance at a hospital where there is a V.D. department. I shall welcome your views upon this question of segregation, because it is obvious that were it to be pushed to an extreme, collaboration would be impossible since the V.D. patient would be prohibited from attending any other department.

To equip and maintain a complete gynacological department would be a quite unnecessary additional expense for a V.D. unit.

To transfer a case of acute gonococcal salpingitis is not usually a convenient, wise or popular procedure. Provision should always exist in a modern lay-out for the gynæcologist, when called in, to carry out such examination and treatment-operative or otherwise-as he may deem necessary. This is assuming, of course, that inpatient female beds are provided.

When the G.-U. and V.D. departments are closely associated, the call upon the gynæcologist is materially increased, and the appointment of such on the staff, with regular days for attendance, is an advantage. This obviates the question of the transfer of a case, and gynæcologists never seem to have beds at their disposal, and, what is more important, the interest in the case is maintained by all concerned and is reflected upon the patient. As a word of warning, and with all the deference due, the activities of the gynæcologist should be clearly confined to only such conditions as definitely complicate our specialties if we are to retain at least some of our beds for our own use.

At my own clinic we are very fortunate in that we are near to a large ophthalmic hospital, and with which we have done our utmost to sustain a very satisfactory mutual working arrangement, under which a patient sent from the one to the other with a letter is seen at once. This is rendered possible because the times at which our sessions are held coincide. The letter, which is a printed form, contains the patient's name or number, provisional diagnosis, treatment already received, and the information sought, and a space is left for the reply. A routine Wassermann and Kahn is taken, and where a positive result is obtained, the case is sent to us for investigation, and not infrequently, in the case of a congenital condition the brothers and sisters are advised to come also. All the cases of interstitial keratitis are sent to us for treat- 


\section{COLLABORATION BETWEEN THE V.D., ETC.}

ment, and numerous cases of iritis for the detection of possible residual foci, etc.

We are careful to interfere in no way with the local treatment of the eye condition, but insist upon the patient's regular attendance for such at the eye hospital, whilst we deal with the general treatment, or local as in the case of a chronic prostatitis. In every instance we endeavour to ensure that the patient reports back to the original sender at regular intervals for assessment of progress, for by this means interest and continuity are sustained in both departments.

Our cases of neuro-syphilis, before and during tryparsamide courses are sent by us for a report upon fundi and visual fields, as are all other cases where advice is deemed necessary. It is very satisfactory to know that at least at one large ophthalmic hospital specific involvement of the eye is no longer treated solely as a local condition.

Apart from a certain amount of mutual respect one would not say that there was very much reciprocity between V.D. and the neurological departments. We, as much as they, probably consider, and rightly, that we are well able to diagnose and treat our own cases of neurosyphilis, and that they come within the province of our own specialty as much as does the case with a primary sore. The only instances in which a one-way transference does occur, therefore, are the exceptional nonspecific cases which occasionally drift into our department. Such cases of neuro-syphilis as are transferred to us come from departments other than the neurological, which may possibly give the latter food for thought in the future. Let us hope, rather, that as a result of our efforts of to-day there will be no cases of neuro-syphilis in the future-in consequence, this bone of contention will be buried.

Our work with the other special departments is comparatively small, and can usually be dealt with by the calling in of a colleague from such for an opinion, just as they might invite one of us, and the transference or nontransference of the case will be mutually agreed upon.

It may at once be said that much that I have touched upon would apply more particularly to the clinic situated in the larger +own or city, and that the greater difficulties with regard $2 u$ collaboration occur in the outlying clinics 


\section{BRITISH JOURNAL OF VENEREAL DISEASES}

in the less densely populated areas. In some of the latter the main difficulty may well be that there is a dearth of special departments with which to co-operate.

Upon the difficulties in collaboration which must have arisen, from time to time, under varied conditions and in different localities, and the measures which have met with most success in their solutions in this country, the experience of Colonel Harrison is unique, and I am sure that we all shall welcome his views upon the subject and profit thereby.

In conclusion, I would suggest that the fundamentals upon which perfect co-operation rest depend upon the esteem with which our specialty is regarded by the other branches of the profession. If it is acknowledged that we have achieved something outside of the scope of their routine, something which is indispensable to them, to be able to give help without detracting from their particular sphere of activity, and cease to be regarded merely as a useful convenience for their dirty work-much will have been done to enhance the prestige of our specialty.

The personal factor must always play a very important part in our mutual dealings, just as it does in any other profession or business, and there invariably must be a repercussion when the individual members of the staff of the one department assist those of another.

In short-" the only way to have a friend is to be one." 